\title{
PERCEPÇÕES E ATITUDES SOCIAIS DE PROFESSORES DE EDUCAÇÃO INFANTIL DE BELO HORIZONTE SOBRE DISFLUÊNCIA NORMAL DA INFÂNCIA E GAGUEIRA
}

\section{SOCIAL PERCEPTIONS AND ATTITUDES OF TEACHERS OF EARLY CHILDHOOD EDUCATION OF BEAUTY ON THE HORIZONT CHILDREN OF NORMAL DISFLUENCY AN STUTTERING}

Fabiane Pereira da Silva ${ }^{1}$, Vanessa Martins-Reis ${ }^{2}$, Rita de Cássia Leite ${ }^{3}$ Letícia Correa Celeste ${ }^{4}$

Resumo: Objetivo: compreender melhor quais são as percepções e atitudes sociais de professores de educação infantil de Belo Horizonte de uma UMEI sobre disfluência normal da infância e gagueira do desenvolvimento. Métodos: participaram deste estudo 11 professoras, as quais responderam um questionário desenvolvido e constituído por dez perguntas referentes à gagueira e disfluência normal da infância. Resultados: das professoras participantes no estudo 54\% relataram já ter lecionado para alguma criança com gagueira; $9 \%$ das professoras acreditam que a disfluência normal da infância pode ocorrer por um período de um a seis meses; a maioria $(72,72 \%)$ das professoras descreveu como causa da gagueira os problemas emocionais. Em relação à atitude a ser tomada com uma criança que esteja gaguejando grande parte das professoras levariam o problema para a direção da escola. Conclusão: por meio desta pesquisa verificouse que as professoras entrevistadas possuem percepções sobre a gagueira e a disfluência normal da infância ora baseadas no senso comum, ora baseadas no conhecimento científico. Percebeu-se ainda que as professoras sabem a importância de se encaminhar as crianças com gagueira para o fonoaudiólogo. 
Palavras-chave: Educação infantil. Gagueira. Percepção. Atitudes.

Abstract: Objective: To better understand what are the perceptions and social attitudes of teachers in early childhood education Belo Horizonte UMEI on a normal childhood disfluency and stuttering development. Methods: participants were 11 teachers, who answered a questionnaire developed and consist of ten questions about stuttering and normal childhood disfluency. Results: the teachers participating in the study $54 \%$ reported having taught for some children who stutter, $9 \%$ of teachers believe that the normal childhood disfluency may occur for a period of 1-6 months, the majority $(72.72 \%)$ of teachers described as a cause of stuttering emotional problems. In the attitude to take with a child who is stuttering most of the teachers would take the issue to the school board. Conclusion: Through this research it was found that the teachers interviewed have perceptions about stuttering and normal disfluency childhood sometimes based on common sense, sometimes based on scientific knowledge. He realized also that the teachers know the importance of children who stutter forward to the audiologist.

Keywords: Early childhood. Stuttering. Perception. Attitudes. 


\section{Introdução}

Criada pela Lei 8679/2003, a Unidade Municipal de Educação Infantil (UMEI) veio melhorar a educação em Belo Horizonte, que até então não contava com escolas infantis públicas que atendessem em horário integral. Segundo a Lei 8679/2003 as Unidades Municipais de Educação Infantil atendem crianças de até cinco anos e oito meses. E é justamente neste período, quando as crianças estão no processo de aquisição e desenvolvimento da linguagem, que pode ocorrer a disfluência normal da infância (BRITO PEREIRA et al., 2001). Em alguns casos a disfluência pode ser prolongada por um tempo além do considerado normal, podendo ocorrer cronificação da gagueira.

A gagueira tem sido classificada segundo o DSM-IV (1995) como uma extrusão no fluxo normal da fala ou agitação da fluência, caracterizada por algumas manifestações que ocorrem frequentemente.

Quando ocorre uma ruptura no fluxo contínuo de fala, ocorre uma disfluência, sendo essa comum a todos os falantes (ANDRADE, 1999). No processo de aquisição e desenvolvimento da fala e da linguagem, a criança pode ter uma disfluência que é caracterizada como um período temporário e natural, denominada como disfluência normal da infância (STUMM, 2001). Segundo Andrade (2004), é comum que as crianças passem por disfluência normal da infância devido à aquisição e desenvolvimento da linguagem, sendo que essa disfluência normal da infância tende a ser eliminada em seis meses.

Definir a gagueira torna-se uma tarefa difícil, uma vez que cada autor defende uma teoria. No entanto, não se pretende no presente estudo realizar uma discussão acerca das diferentes teorias, mas sim apresentar algumas definições sobre a gagueira e seus subtipos. 
Launay e Borel-Maisonny (1989) classificam a gagueira como sendo uma desordem, na qual o ritmo da fala está prejudicado sem que estejam evidentes "alterações" nos órgãos fonoarticulatórios, e está relacionada à "presença de um interlocutor, dificuldades psicológicas e conflitos interiores".

Para Andrade (2004), a gagueira pode ser dividida em três subgrupos, sendo eles: gagueira neurogênica, gagueira psicogênica (ambas tidas como gagueiras adquiridas) e gagueira idiopática ou do desenvolvimento, esta última será o foco deste estudo.

A gagueira neurogênica ocorre por uma lesão cerebral, podendo esta ser de origem traumática ou vascular, acometendo pessoas fluentes. Já a gagueira psicogênica ocorre por algum acontecimento psicológico, podendo estar relacionada a problemas emocionais ou psiquiátricos (ANDRADE, 2004).

A gagueira idiopática ou do desenvolvimento ocorre na infância (entre os 18 meses e os sete anos, podendo se manifestar até os 12 anos). Esse subtipo pode apresentar episódios recorrentes, sendo caracterizada como um desvairamento de origem crônica, mesmo que ocorra em espaços de tempo diferentes da fala. Esse tipo de gagueira pode ser definido também como sendo o “[...] resultado de problemas no sistema nervoso central tendo base genética, que podem trazer problemas psicossociais ao indivíduo." Esse subtipo é encontrado em $80 \%$ dos casos de gagueira que são diagnosticados na infância, sendo a prevalência de cronificação de 20\% (ANDRADE, 2004).

Segundo Andrade (1999), alguns traços podem predispor a ocorrência da gagueira, sendo que estes podem ser divididos em: hereditários, biológicos, linguísticos e sociais.

Para Dinville (1993), outro fator importante é o escolar. Uma vez que é na faixa etária entre três e quatro anos de idade, quando a criança começa a produzir suas primeiras frases e aumenta a relação com outros indivíduos, que a maior parte das crianças apresenta disfluências, que tendem a regredir à 
medida que seus elementos linguísticos se tornem satisfatórios. Dinville (1993) afirma que a gagueira pode ter início em outras crianças entre cinco e seis anos, exatamente quando ingressam na escola primária. Segundo Luz e Campiotto (apud GOMES, 1998), é preciso que os professores tenham "conhecimento não só dos processos de aquisição e desenvolvimento da linguagem", mas que tenham conhecimento também sobre os distúrbios da comunicação. O professor desempenha um papel importante na vida da criança, por ser ele quem estimula o desenvolvimento da criança. Em um estudo, Launay e Borel-Maisonny (1989) afirmam que a gagueira sofre influência primeiramente na família e segundo na escola. Sendo assim, Chiquetto (1992) considera importante ponderar os aspectos pertencentes ao ambiente escolar, principalmente estar atento ao relacionamento entre aluno-professor, pois é o professor entre todos do universo escolar que tem melhor relação com a criança e por um período maior. A autora demonstra que alguns professores relatam ter problemas para assinalar a gagueira, considerando apenas características isoladas, podendo ser confundidas com disfluência normal da infância ou com outras patologias.

Os professores apresentam percepções e atitudes distintas com crianças que gaguejam, sendo essas percepções parecidas com as percepções de senso comum, ou seja, embora bem "intencionadas são consideradas inadequadas” (CHIQUETTO, 1992).

Diante disso, o presente estudo tem como objetivo compreender melhor quais são as percepções e atitudes sociais de professores de educação infantil de Belo Horizonte (UMEI) sobre disfluência normal da infância e gagueira do desenvolvimento.

Diante das pesquisas realizadas, acredita-se que os professores de educação infantil de Belo Horizonte (UMEI) tenham pouca percepção ou uma percepção inadequada sobre disfluência normal da infância e gagueira do desenvolvimento; e que por 
causa disso não saibam quais atitudes devem ter frente à criança que apresenta disfluência normal da infância e gagueira do desenvolvimento.

\section{Materiais e métodos}

Trata-se de um estudo transversal descritivo, realizado de fevereiro a junho de 2012, que foi aprovado pelo Comitê de Ética em Pesquisa Envolvendo Seres Humanos (CEP) da Faculdade de Estudos Administrativos de Minas Gerais (FEAD), sob o protocolo n. 209. Todas as professoras que lecionam em uma Unidade Municipal de Educação Infantil (UMEI) foram contatadas a participar da pesquisa. Dessas, somente 16 responderam ao questionário, porém cinco questionários foram excluídos da amostra por não preencherem os critérios de inclusão, constituindo a amostra final de 11 questionários respondidos.

Para participação no presente estudo foram adotados os seguintes critérios de inclusão: professores que lecionem para faixa etária de três a cinco anos e oito meses; Assinatura do Termo de Consentimento Livre e Esclarecido e Preencher completamente o questionário aplicado.

Foram excluídos os professores com formação em Fonoaudiologia ou que tenham recebido treinamento fonoaudiológico a respeito das alterações de linguagem ou treinamento específico sobre gagueira.

Para realização desta pesquisa, a coordenadora pedagógica da instituição assinou a Carta de Autorização e todos os professores que aceitaram fazer parte desse trabalho assinaram o Termo de Consentimento Livre e Esclarecido (TCLE). Em seguida, as professoras responderam o questionário desenvolvido por Celeste et al. (no prelo, adaptado pelas autoras), na sala destas 
em um horário previamente combinado e de forma individual, sendo estimado o tempo médio de 15 minutos para respondê-lo.

O questionário é constituído de dez perguntas, sendo duas questões abertas e oito questões fechadas. A primeira questão refere-se à identificação pessoal e profissional do professor. A segunda questão busca verificar se o professor já lecionou para alunos com gagueira. As questões de três a sete buscam averiguar quais percepções os professores tem sobre disfluência normal da infância e gagueira. A oitava questão questiona quais atitudes o professor tem diante de um aluno que apresenta gagueira. Com a questão de número nove é possível perceber se a escola fornece recursos para que o professor aprenda mais sobre a gagueira, para finalizar o questionário, os professores descreveram o que definem como gagueira.

Após a coleta, os dados foram tabulados no programa Microsoft Office Excel versão 2007 para análise estatística. Foi realizada análise descritiva por meio de tabelas de frequência.

\section{Resultados e discussão}

A faixa etária das professoras participantes no estudo encontrase entre 26 e 54 anos. Quanto à escolaridade, sete professoras $(63,6 \%)$ possuem curso superior completo em Pedagogia, uma $(9,09 \%)$ possui curso completo de Normal Superior, uma (9,09\%) possui pós-graduação em Psicopedagogia, uma (9,09\%) possui pós-graduação em Educação Especial e uma (9,09\%) está cursando Pedagogia.

Por meio da análise dos questionários, 54\% das professoras entrevistadas relataram já ter lecionado para alguma criança com gagueira. Esse achado era esperado uma vez que os dados do Instituto Brasileiro de Fluência (MERLO, 2006/2007) 
revelam que a incidência de gagueira é de 5\% na população brasileira, ou seja, aproximadamente dez milhões de brasileiros estão passando por um período de gagueira.

A partir da pergunta de número três, pesquisou-se o conhecimento das professoras sobre gagueira. Foi possível verificar que $27 \%$ das professoras consideram normal a criança gaguejar em algum momento, o que difere do encontrado em estudo realizado com mães de crianças que gaguejam, no qual $50 \%$ das entrevistadas acreditam ser normal a criança gaguejar por algum tempo, durante o período de desenvolvimento (DELEGRACIA; GALVÃO, 2004). Castro (2011) realizou estudo a fim de verificar o conhecimento, concepções e atitudes de professores do ensino fundamental de uma escola pública, antes e após intervenção em saúde comunicativa. Como resultado verificou-se que antes da atividade de promoção em saúde a maioria das professoras (62,5\%) respondeu que não é normal a criança gaguejar por algum tempo, porém após orientação observou-se que $75 \%$ das professoras acreditam ser normal a criança gaguejar por um período.

Das três professoras que acreditam ser normal a criança gaguejar, $100 \%$ dessas acreditam que o início e o final da gagueira deve ocorrer de um a seis anos. Segundo Andrade (2004), a gagueira pode ter início entre os 18 meses até os 12 anos, corroborando com o descrito pelas professoras de educação infantil, no que se refere à idade considerada normal para o início da gagueira.

As professoras que acreditam ser normal a criança gaguejar por algum tempo responderam ainda a questão de número cinco. Dessas, $9 \%$ acreditam que a disfluência normal da infância pode ocorrer por um período de um a seis meses. Segundo Brito Pereira et al. (2001), a disfluência normal da infância é uma fase normal e passageira, que ocorre em várias crianças, em torno dos dois aos cinco anos. A autora afirma ainda que existem casos 
em que podem ocorrer à manutenção do sintoma por um tempo maior que o esperado, aproximadamente seis meses, podendo a partir daí não regredir mais.

Ao serem questionadas sobre a etiologia da gagueira, a maioria das professoras descreveu como causa da gagueira os problemas emocionais (Tabela 1). Esse achado corrobora com o descrito por Rossi (2008), ao relatar que 56,9\% dos homens e mulheres entrevistados descreveram o aspecto emocional como sendo a causa da gagueira. Van Borsel et al. (apud ROSSI, 2008) realizou estudo na Bélgica no qual 1.362 sujeitos responderam questionário referente à gagueira. Ao serem questionados sobre a etiologia da gagueira, $45 \%$ dos participantes responderam ser a gagueira de origem psicogênica e 11,9\% como causa desconhecida.

No senso comum há certa tendência ao se considerar que o indivíduo não nasce gago, mas se torna gago por algum acontecimento (BARBOSA; CHIARI, 1998). No conhecimento científico, existem diversas teorias que descrevem a etiologia da gagueira. Para Andrade (1999) e Jakubovicz (1997), a etiologia mais aceita ao se tratar de gagueira do desenvolvimento é o fator genético.

Tabela 1 - Frequência e porcentagem das respostas obtidas nos questionários quanto à etiologia da gagueira

\begin{tabular}{|c|c|c|}
\hline Etiologia & $\mathbf{N}$ & $\mathbf{\%}$ \\
\hline Emocional & 8 & $72,72 \%$ \\
\hline Genética & 4 & $36,36 \%$ \\
\hline Meio Social & 3 & $27,27 \%$ \\
\hline Personalidade & 1 & $9,09 \%$ \\
\hline Outros & 1 & $9,09 \%$ \\
\hline Não sei & 1 & $9,09 \%$ \\
\hline
\end{tabular}

Fonte: elaboração das autoras. 
As professoras foram questionadas ainda sobre a cura da gagueira. Como resultado, 45\% das professoras (Gráfico 1) acreditam que a gagueira tem cura. Considerando esse dado, as professoras descreveram ainda que a "idade limite" para a cura da gagueira é de até seis anos. Resultados semelhantes foram descritos por Carvalho e Galvão (2006), ao relatar que 64,4\% dos sujeitos gagos participantes de seu estudo acreditam na cura da gagueira.

Gráfico 1 - Porcentagem de cura da gagueira por meio das respostas dos questionários

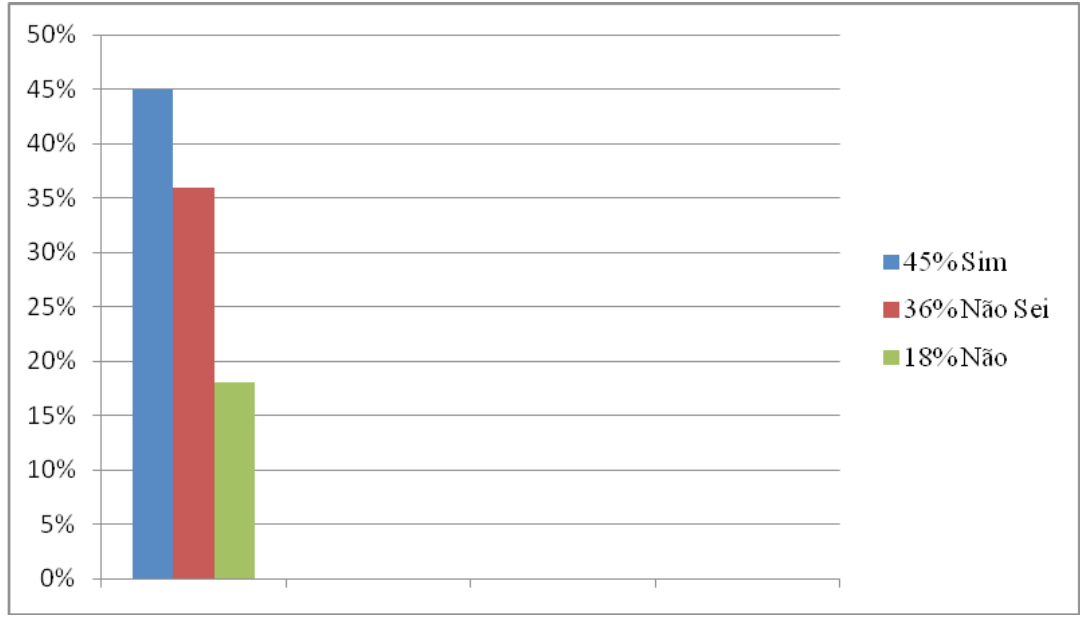

Fonte: elaboração das autoras.

Ao serem interrogadas sobre a atitude a ser tomada com uma criança que esteja gaguejando, a maioria das professoras afirma levar o problema para a direção da escola. Na sequência observou-se que as professoras marcariam uma reunião com os pais da criança e encaminhariam para um especialista, sendo que $100 \%$ dessas encaminhariam para o fonoaudiólogo (Gráfico 2). Segundo Gregory (apud STUMM, 2001), diante de uma 
criança que gagueja o professor não deve se preocupar com sua fala, mas sim encaminhá-la para um especialista e conversar com os pais sobre sua dificuldade na fala. Feriolli (2005) realizou estudo para investigar o conhecimento e atitudes de professores de escolas públicas e particulares do ensino fundamental de São Paulo sobre gagueira. Os autores concluíram que 72,7\% dos professores acreditam ter conhecimento sobre a gagueira, porém esse conhecimento advém do senso comum, e por isso os mesmos têm insegurança para lidar com crianças que apresentam gagueira.

Gráfico 2 - Distribuição das respostas quanto às atitudes a serem tomadas com crianças que gaguejam (opção de mais de uma resposta)

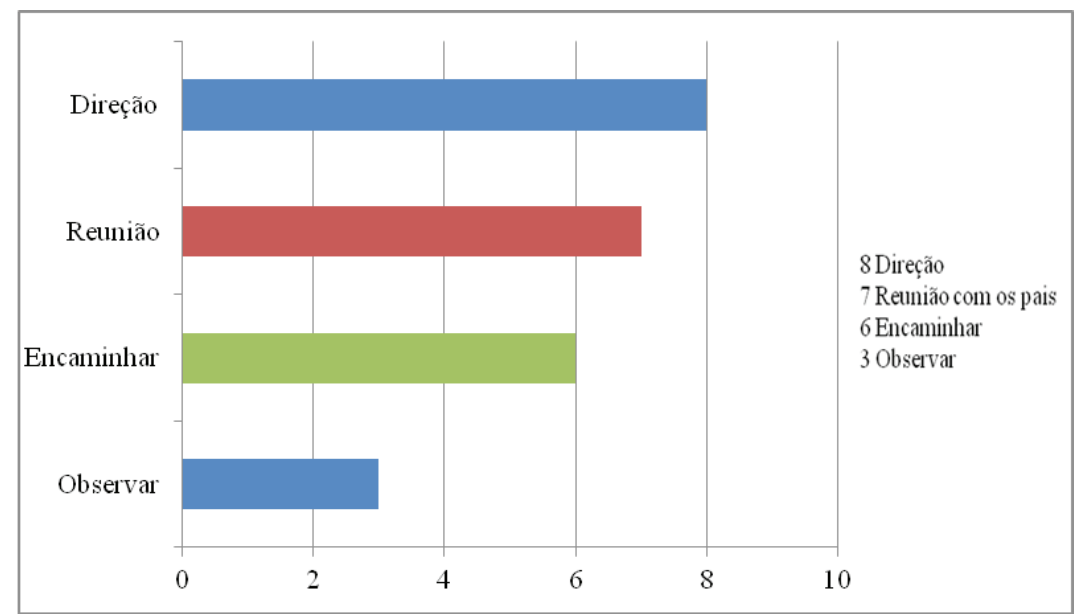

Fonte: elaboração das autoras.

Silva (2011) realizou estudo sobre a percepção dos acadêmicos de pedagogia dos períodos iniciais e finais de universidades públicas em relação à gagueira. Para o estudo utilizou-se o 
mesmo questionário aplicado na presente pesquisa. A autora revela que para os graduandos em Pedagogia a atitude mais tomada frente a uma criança que gagueja seria encaminhar para o fonoaudiólogo, marcar uma reunião com os pais e levar o problema para a direção da escola. Segundo Andrade (1999), com o surgimento dos primeiros sintomas de disfluência, os pais devem ser orientados a buscar ajuda de um profissional competente, evitando assim que a gagueira seja instalada.

Estudo realizado por Jorge (2007) com alunos de Magistério e Pedagogia buscou caracterizar o conhecimento desses alunos sobre os aspectos fonoaudiológicos (fala e linguagem, gagueira, leitura e escrita, audição e voz), além de comparar esses conhecimentos antes e depois de desenvolvimento de um programa de orientação fonoaudiológica. A autora concluiu que antes e após o programa a maioria dos participantes mostrou saber o conceito de gagueira, $\mathrm{e}$ a minoria disse saber lidar com alunos que gaguejam. Esse estudo confirmou os achados de Chiquetto (1992) ao descrever que a maioria dos profissionais de educação infantil tem dificuldades para lidar com crianças que apresentam gagueira e em alguns casos existe uma negação em relação à gagueira.

De acordo com 100\% das professoras, nunca foi realizado na UMEI qualquer evento sobre a gagueira. Para Stumm (2001), é de extrema importância que os professores recebam orientações relacionadas ao processo de aquisição e desenvolvimento da linguagem, com o intuito de fazer com que os professores tenham conhecimento adequado sobre a ocorrência das disfluências e saibam como lidar com alunos que apresentem gagueira.

Quando as professoras foram indagadas a responder sobre o que é gagueira, verificaram-se respostas diversas. Das respostas apresentadas podemos citar: disfunção/dificuldade da fala (7); distúrbio nas pregas vocais (1); sílabas repetitivas expressadas com esforço vocal (1); processamento rápido das informações (1); apenas uma professora relatou não saber o que é gagueira 
(Gráfico 3). Um estudo realizado por Stumm (2001) revelou que alguns professores ao descreverem a gagueira baseiam-se no ponto de vista articulatório, considerando uma definição baseada no senso comum. Esse achado corrobora com os dados encontrados na UMEI pesquisada, uma vez que as professoras acreditam ser a gagueira um problema articulatório.

Gráfico 3 - Número de respostas obtidas nos questionários quanto ao conceito de gagueira

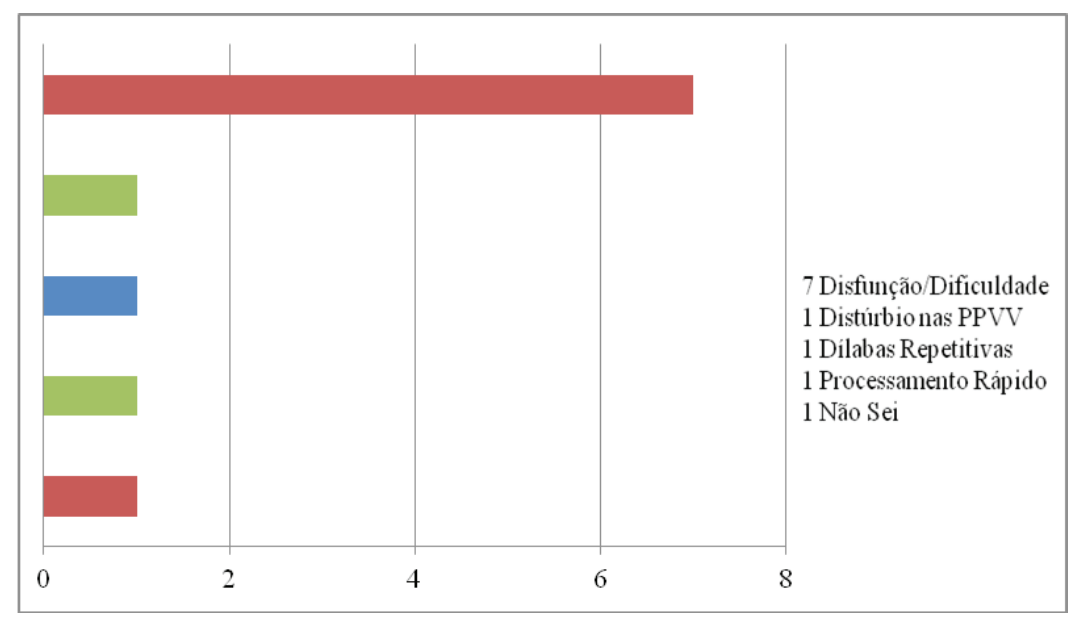

Fonte: elaboração das autoras.

Durante a aplicação dos questionários foi observada dificuldade das professoras para separarem o conhecimento científico do senso comum. Esse fato foi observado também por Barbosa et al. (1993), ao realizar um estudo com estudantes de fonoaudiologia. A autora verificou que, mesmo com um conhecimento prévio sobre o que é gagueira, os alunos possuem um "preconceito" contra a gagueira e o indivíduo que gagueja, baseando-se no senso comum, ao concordarem ou discordarem com afirmações sobre a gagueira. 
Celeste et al. (no prelo) em estudo realizado com trezentos professores de escolas municipais, estaduais e particulares de Belo Horizonte e região Metropolitana, concluíram que, ao responderem questões referentes a gagueira, os professores baseiam-se mais no senso comum que no conhecimento científico.

\section{Conclusão}

Por intermédio da análise dos questionários, foi possível compreender quais são as percepções dos professores sobre a gagueira e quais são as principais atitudes que esses professores têm com alunos que apresentam gagueira ou disfluência normal da infância.

Por meio desta pesquisa, verificou-se que as professoras entrevistadas possuem percepções sobre a gagueira e a disfluência normal da infância ora baseadas no senso comum, ora baseadas no conhecimento científico.

Em relação às atitudes frente às crianças que apresentam disfluência normal da infância e gagueira do desenvolvimento, percebeu-se que as professoras sabem a importância de se encaminhar as crianças com gagueira para o fonoaudiólogo, além de orientarem os pais sobre a fala da criança.

Após a análise dos resultados aqui apontados, questiona-se a necessidade de debates e discussão entre fonoaudiólogos e pedagogos sobre a gagueira, a fim de ampliar o conhecimento dos professores de Educação Infantil sobre disfluência normal da infância e gagueira do desenvolvimento. 


\section{Referências}

ANDRADE, C. R. F. Abordagem Neurolinguística e Motora da Gagueira. In: FERREIRA, L. P.; BEFI-LOPES, D. M.; LIMONGI, S. C. O. Tratado de Fonoaudiologia. São Paulo: Rocca, 2004. Cap. 80, p. 1001-1016.

- Diagnóstico e Intervenção Precoce no Tratamento das Gagueiras Infantis. Carapicuiba: Pró-Fono, 1999. 112 p.

BARBOSA, L. M. G. et al. Gagueira: a manifestação do preconceito em estudantes de fonoaudiologia. 1993. 7 f. Monografia - Escola Paulista de Medicina, São Paulo, 1993.

BARBOSA, L. M. G.; CHIARI, B. M. Gagueira: etiologia, prevenção e tratamento. Carapicuiba: Pró-Fono, 1998. 97 p.

BRASIL. PREFEITURA DE BELO HORIZONTE. Lei 8679 de 11 de novembro de 2003. Cria as Unidades Municipais de Educação Infantil e o Cargo de Educador Infantil, Altera as Leis NoS 7.235/96 e 7.577/98 e dá outras Providências. Belo Horizonte, 2003. Disponível em: <http:// www. leismunicipais.com. br>. Acesso em: 17 fev. 2012.

BRITO PEREIRA, M. M. et al. Disfluência Infantil: Tratamento Direto x Indireto. Revista Fono Atual, São Paulo, n. 15, p. 10-15, mar. 2001.

CARVALHO, A. P. G.; GALVÃO, V. S. Concepções e Atitudes de Sujeitos Gagos sobre a Gagueira. Revista de Iniciação Científica da FFC, São Paulo, v. 5, n. 1, 2, 3, p. 15-24, 2006.

CASTRO, M. E. Gagueira do desenvolvimento e disfluência normal na infância: conhecimento, concepções e atitudes de professores antes e após atividade de prevenção em saúde comunicativa. 2011. 33 f. Monografia - Faculdade de Estudos Administrativos de Minas Gerais, 2011.

CELESTE, L. C. et al. Um Olhar Pedagógico sobre a Gagueira. 2010. No prelo. 
CHIQUETTO, M. M. Reflexões sobre a Gagueira: Concepções e Atitudes dos Professores. 1992. 135 f. Dissertação (Mestrado em Letras - Lingüística) - Universidade Federal de Santa Catarina, Florianópolis, 1992.

DELEGRACIA, J. D.; GALVÃO, V. S. O Conhecimento de Mães e Professores das Séries Iniciais Sobre a Gagueira de Crianças em Fase Inicial de Escolarização. Revista de Iniciação Científica da FFC, São Paulo, v. 4, n. 2, p. 136-151, 2004.

DINVILLE, C. A gagueira: Sintomatologia e Tratamento. Rio de Janeiro: Enelivros, 1993. 164 p.

DSM. IV Manual diagnóstico e estatístico de transtornos mentais. 4. ed. Porto Alegre: Artes Médicas, 1995.

FERIOLLI, B. H. V. M. et al. O Conhecimento e as Atitudes dos Professores frente à Gagueira. Jornal Brasileiro de Fonoaudiologia, p. 3, 2005.

GOMES, D. L. O Papel do professor na formação da imagem de falante do aluno. 1998, 23 f. Monografia (Especialização em Linguagem) Centro de Especialização em Fonoaudiologia Clínica, São Paulo, 1998.

JAKUBOVICZ, R. A gagueira: teoria e tratamento de adultos e crianças. Rio de Janeiro: Revinter, 1997. 203 p.

JORGE, T. M. Programa de Orientação Fonoaudiológica a Alunos dos Cursos de Magistério e Pedagogia. 2007. 171 f. Dissertação (Mestrado em Ortodontia e Odontologia) - Universidade de São Paulo, Bauru, 2007.

LAUNAY, C. L.; BOREL-MAISONNY, S. Distúrbios da linguagem, da fala e da voz na infância. São Paulo: Rocca, 1989. 350 p.

MERLO, Sandra. Instituto Brasileiro de Fluência - IBF. Tratamentos da gagueira: Dúvidas sobre tratamento da gagueira. 2006-2011. Disponível 
em: <http://www.gagueira.org.br/conteudo.asp?id >. Acesso em: 12 maio 2012.

ROSSI, J. P. Conhecimento da população do Rio de janeiro sobre a gagueira. 2008. 47 f. Dissertação (Mestrado Profissionalizante em Fonoaudiologia) - Universidade Veiga de Almeida, Rio de Janeiro, 2008.

SILVA, M. A. O. A Percepção dos acadêmicos de pedagogia dos períodos iniciais e finais de universidades públicas em relação à gagueira. 2011.35 f. Monografia - Faculdade de Estudos Administrativos de Minas Gerais, 2011.

STUMM, L. C. Gagueira: o professor e a criança. Bauru: Ed. Universidade do Sagrado Coração, 2001. 106 p.

\section{Notas}

${ }^{1}$ Graduada em Fonoaudiologia. Centro de Gestão Empreendedora FEAD. Área de atuação: linguagem e fluência. Endereço para contato: rua Begônia, n. 304, Santa Margarida. Cidade: Ribeirão das Neves, CEP: 33920-340. Correspondência com leitores: <fabyfono@hotmail.com>.

${ }^{2}$ Doutora em Linguística pela Universidade de São Paulo, professor adjunto da Universidade Federal de Minas Gerais. Área de atuação: linguagem, fonoaudiologia escolar e fluência.

${ }^{3}$ Mestre em Ciências da Saúde pela Universidade Federal de Minas Gerais. Professor assistente do Centro de Gestão Empreendedora FEAD. Área de atuação: linguagem.

${ }^{4}$ Doutora em Linguística pela Universidade Federal de Minas Gerais. Professor adjunto do Centro de Gestão Empreendedora FEAD. Área de atuação: linguagem e fluência. 